\title{
Extraordinary Opportunity: Research on Tobacco and Tobacco Related Cancers
}

National Cancer Institute

\section{Source}

National Cancer Institute. Extraordinary Opportunity: Research on Tobacco and Tobacco

Related Cancers. NCI Thesaurus. Code C16139.

Goal : to expand our understanding of tobacco addiction and the biological mechanisms underlying tobacco-induced cancers, develop ways to keep people of all ages from using tobacco, create interventions to prevent tobacco-related cancers in smokers and former smokers, and develop treatments for tobacco addiction and the cancers it causes. (from $\mathrm{NCl}$ Initiatives Web page) 